Article

\title{
Breeding of the Dormant Thermosensitive Genic Male-Sterile Lines of Early Rice to Overcome Pre-Harvest Sprouting of the Hybrid Seeds
}

\author{
Xiaoyu Chen, Yun Tian * and Xiangyang Lu * \\ College of Bioscience and Biotechnology, Hunan Agricultural University, Changsha 410128, China; \\ xiyuchn@163.com (X.C.) \\ * Correspondence: tianyun79616@163.com (Y.T.); xiangyangcn@163.com (X.L.); \\ Tel./Fax: +86-731-84635292 (Y.T.)
}

Received: 16 August 2018; Accepted: 13 September 2018; Published: 16 September 2018

\begin{abstract}
The pollen development of male-sterile lines should be conducted during the high temperature season to ensure the sterility of male-sterile line pollen and the safety of hybrid seed production in the breeding of thermosensitive genic male-sterile (TGMS) lines of early rice. However, the mature hybrid rice seeds are prone to pre-harvest sprouting (PHS) during hot, rainy days, which leads to the decrease of hybrid rice seed quality or a loss of utilization value. In this study, with an aim to bring a dormancy trait from the dormant genotype to the current low-dormant TGMS lines, a common wild rice "Chaling" (Oryza rufipogon), which has strong seed dormancy, a large black stigma, and a high exsertion rate, was hybridized with the early rice TGMS line "Zhu 1S," which often exhibits PHS. After screening for early maturing and seed dormancy, the early rice "Yezao S" and "Yezhuzao S," with the characteristic of seed dormancy, were selected. The critical temperature of high temperature sterility for these two male-sterile lines was below $23.5^{\circ} \mathrm{C}$. The stigma of "Yezao $\mathrm{S}^{\prime \prime}$ was black and its exsertion rate was 79.9\%, while "Yezhuzao S" had a colorless stigma with an exsertion rate of $76.8 \%$. The expression of the genes OsNCEDs in "Yezao S" and "Yezhuzao S" were

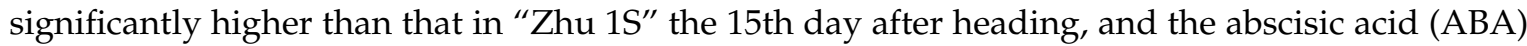
content was also higher than that of "Zhu 1S" the 20th day after heading. The results indicated that introducing the dormancy characteristics from wild rice "Chaling" into the early rice TGMS lines was an effective way to prevent PHS.
\end{abstract}

Keywords: rice (Oryza sativa L.); seed; dormancy; thermosensitive genic male-sterile (TGMS) lines; pre-harvest sprouting (PHS); abscisic acid (ABA)

\section{Introduction}

Rice (Oryza sativa L.) is one of the main grain crops in the world. The rice growing regions in the middle and lower reaches of the Yangtze River and in South China allow for double cropping of early and late rice; these areas are also the main growing regions of hybrid rice. Thermosensitive genic male-sterile (TGMS) lines, male-sterile at restrictive (high) temperatures but male-fertile at permissive (low) temperatures [1,2], have been widely used in breeding two-line hybrid rice [3,4]. The high temperature season is the most stable period for pollen sterility in TGMS lines and is also the most secure period for hybrid seed production. However, under this condition, hybrid rice seeds are prone to pre-harvest sprouting (PHS) on rainy days [5,6]. "Zhu 1S" (O. sativa ssp. indica), which was bred in 1998 , is a TGMS line of early rice $[7,8]$. Presently, there are 32 high-yielding hybrid rice combinations, which significantly improve the yield of early hybrid rice [9]. The first super hybrid early rice line approved by the state, "Zhuliangyou 819", which takes Zhu $1 \mathrm{~S}$ as its female parent and Hua 819 as 
its male parent, is used as the control variety in national regional trials. However, without dormancy, the hybrid seeds produced by "Zhu 1S" are prone PHS, and the risk of seed production is quite high. Therefore, there is an urgent need for breeding sterile lines of early rice with dormancy characteristics to prevent seed PHS.

Seed dormancy is a physiological phenomenon in which an intact mature seed with normal life vitality does not germinate under suitable environmental conditions (light, temperature, water, and oxygen etc.) [10]. It is a protective mechanism for plants for long-term adaptation to environmental and seasonal changes. By adjusting the best time and spatial distribution of seed germination, plants can adapt to adverse environments [11,12]. The seed dormancy of wild rice is stronger than that of cultivated rice [13]. For example, the common wild rice "Chaling" (Oryza rufipogon), distributed in higher latitudes $\left(26^{\circ} 50^{\prime} \mathrm{N}\right)$, is a typical short-day plant, which has strong seed dormancy, a large black stigma, and a high exsertion rate; it heads on approximately September 20th and matures at the end of October. In this paper, early rice materials with seed dormancy and the TGMS line of early rice were bred from hybrid progenies of "Zhu 1S" and Oryza rufipogo. Using "Zhu 1S" and "Hua 819" as controls, the gene expression difference of NCEDs and the abscisic acid (ABA) content were compared. The results of this study were of great significance to prevent seed PHS of hybrid early rice.

\section{Materials and Methods}

\subsection{Materials}

Rice materials included Zhu 1S, Hua 819, Yezao 1, Yezao S, and Yezhuzao S.

The TGMS line of early rice, "Zhu 1S," in which PHS occurs easily, is the female parent of super hybrid early rice "Zhuliangyou 819 ," while "Hua 819 " is its male parent. "Yezao S" is the hybrid

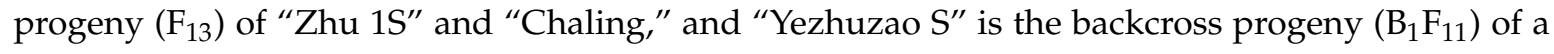
precocious single plant of the hybrid F2 generation and "Zhu 1S." "Yezao 1" is a fertile early rice hybridized from "Chaling" and "Zhu 1S," which is the control of Yezao S.

\subsection{Methods}

\subsubsection{Germination Tests}

The freshly harvested seeds were surface-sterilized with $70 \%$ ethanol for $1 \mathrm{~min}$, then sterilized with $0.41 \%$ sodium hypochlorite solution for $15 \mathrm{~min}$ and rinsed with sterile double-distilled water for $5 \mathrm{~min}$. One hundred seeds were then placed in a polymethyl methacrylate germinating box and cultured in a growth chamber (Zhujiang, Guangzhou, China) at $30^{\circ} \mathrm{C}$.

Germinated seeds that had a radicle or plumule of at least $2 \mathrm{~mm}$ were counted and removed every day until the 7th day after incubation. Every experiment was repeated three times.

\subsubsection{Pollen Fertility Identification of the TGMS Lines and Seed Propagation Method of Male-sterile Lines}

Each male-sterile line was planted in 10 pots, with 4 plants per pot. The young panicle was treated at a constant temperature water bath at $23.5^{\circ} \mathrm{C}$ for 6 days under natural light and temperature conditions until the potted male-sterile line plants developed to the pollen mother cell stage. After the treatment, the pots were kept under naturally high temperature conditions, and pollen fertility was detected by $1 \%$ I-KI solution during the flowering period [14].

The breeding of the male-sterile lines was carried out in Changsha and in Sanya. In Changsha, when the young panicle of the potted male-sterile line developed to the stage of the pollen mother cell, it was treated in a constant temperature water bath at $20.5^{\circ} \mathrm{C}$ for 18 days. After, the pots were moved to natural high temperature conditions, and the male-sterile line plants could restore pollen fertility and produce male-sterile line seeds. And in Sanya, the breeding was implemented by natural low temperature conditions in the spring, in which the male-sterile lines can produce self-fed seeds. 


\subsubsection{Measurement of ABA Content}

Filled grains were collected 20 days after heading, and seeds $(300 \mathrm{mg})$ were ground in liquid nitrogen. The powder was extracted with $1.5 \mathrm{~mL}$ of extraction solution (methanol: $\mathrm{H}_{2} \mathrm{O}$ : methanoic acid in a ratio of 7.9:2:0.1) and kept overnight at $4{ }^{\circ} \mathrm{C}$. The samples were centrifuged at 12,000 $\mathrm{g}$ for $20 \mathrm{~min}$ at $4{ }^{\circ} \mathrm{C}$. The supernatant was collected, dried under nitrogen gas, and dissolved in $2 \mathrm{~mL}$ of $0.1 \mathrm{M}$ ammonia solution. Crude extracts were purified using a MAX column that was pre-treated with $2 \mathrm{~mL}$ methanol and then with $2 \mathrm{~mL} 0.1 \mathrm{M}$ ammonia solution. After the supernatant was loaded onto the MAX column, the column was washed with $2 \mathrm{~mL}$ of $0.1 \mathrm{M}$ ammonia solution followed by $2 \mathrm{~mL}$ of methanol. ABA was eluted with $4 \mathrm{~mL}$ of methanol containing $1 \%$ methanoic acid. The eluent was dried under nitrogen gas and dissolved in $0.2 \mathrm{~mL}$ of methanol and then filtered through a $0.2 \mu \mathrm{m}$ nylon membrane. The internal standard used was $\left[{ }^{2} \mathrm{H}_{6}\right]$ ABA. ABA levels were quantified using liquid chromatography-tandem mass spectrometry (LC-MS/MS) with 3 biological replicates.

\subsubsection{Quantitative Real-Time PCR Analysis}

Total RNA was extracted from rice seeds (filled grains were collected 15 days after heading) using Trizol according to the manufacturer's instructions (Thermo Fisher Scientific, Waltham, MA, USA). Approximately $1 \mu \mathrm{g}$ of total RNA was used for first-strand cDNA synthesis with the Synthesis Kit (Thermo Fisher Scientific, USA). The reaction products were diluted 10-fold and used as the template for real-time PCR with 3 biological replicates using the SYBR Premix Ex Taq kit (Takara, Dalian, China). qRT-PCR was performed with an Applied Biosystems Quant Studio 5 (Thermo Fisher Scientific, Waltham, MA, USA) real-time PCR System. The primer sequences of qRT-PCR refer to Table 1.

Table 1. OsNCED genes primers.

\begin{tabular}{cc}
\hline Primer Name & Primer Sequence \\
\hline ACTIN F & $5^{\prime}$-CAATGTGCCAGCTATGTATGTCGCC-3' \\
ACTIN R & $5^{\prime}$-TTCCCGTTCAGCAGTGGTAGTGAAG-3' \\
OsNCED1F & $5^{\prime}$-CTCACCATGAAGTCCATGAGGCTT-3' \\
OsNCED1R & $5^{\prime}$-GTTCTCGTAGTCTTGGTCTTGGCT-3 $3^{\prime}$ \\
OsNCED2F & $5^{\prime}$-TGCGAATCTGACCTTCCCTACT-3 ${ }^{\prime}$ \\
OsNCED2R & $5^{\prime}$-TGCGACCTTGCTGCCTGCTC-3 $3^{\prime}$ \\
OsNCED3F & $5^{\prime}$-CCCCTCCCAAACCATCCAAACCGA-3 \\
OsNCED3R & $5^{\prime}$-TGTGAGCATATCCTGGCGTCGTGA-3' \\
OsNCED4F & $5^{\prime}$-CGTGTCCAAGCCGTACCT-3' $3^{\prime}$ \\
OsNCED4R & $5^{\prime}$-CGACGCCTTCTCCCTGT-3 $3^{\prime}$ \\
OsNCED5F & $5^{\prime}$-ACATCCGAGCTCCTCGTCGTGAA-3' \\
OsNCED5R & $5^{\prime}$-TTGGAAGGTGTTTGGAATGAACCA-3' \\
\hline
\end{tabular}

\section{Results}

\subsection{Breeding TGMS Lines "Yezao S" and "Yezhuzao S"}

In September 2011, 78 seeds of the hybrid $F_{1}$ generation were obtained from the hybridization of "Zhu 1S" (female parent) and wild rice "Chaling" (male parent). Under the conditions of a short day and higher temperature in Sanya, Hainan, $62 \mathrm{~F}_{1}$ generation plants were obtained by sowing the F1 seeds in November. The mixed $\mathrm{F}_{2}$ seeds were harvested in March 2012 and soaked on the same day for seed germination screening at suitable natural conditions in Sanya. The seeds germinated within seven days were removed, and the ungerminated seeds were air dried and treated with 100 ppm GA 3 to relieve dormancy in Changsha. After germination, a total of 2000 plants were planted. By observing their growth, the precocious single plants that took no more than 75 days from sowing to heading were selected as the breeding objects of an early rice type. After detecting dormancy characteristics, the seeds were planted to obtain the early rice TGMS lines with seed dormancy. In addition, the TGMS lines of 
early rice with strong seed dormancy were screened out from the backcross progeny of "Zhu $1 S^{\text {" and a }}$ single plant with the earliest heading was selected as the male parent. Through additional propagation and screening in Changsha and Sanya, the early rice TGMS lines "Yezao S" (F13) and "Yezhuzao S" (B1F11) with stable characteristics were acquired in 2017.

The selected seeds were sown on 25th March 2018 in Changsha and transplanted on 15th April with routine management of fertilizer and water. The initial heading period and mature period of each line were recorded, while the mature period of male-sterile lines was observed after artificial pollination. As shown in Table 2, "Yezao 1" was the very early maturity type and the TGMS lines of "Yezao S" and "Yezhuzao S" were early maturity types. "Hua 819" was the male parent of "Zhuliangyou 819,"

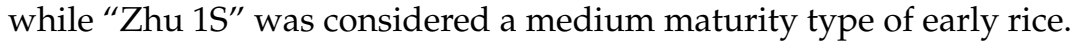

Table 2. Comparison of the growth period of different rice lines.

\begin{tabular}{cccccc}
\hline Lines & $\begin{array}{c}\text { Sowing Date } \\
\text { (Day/Month) }\end{array}$ & $\begin{array}{c}\text { Initial Heading } \\
\text { Date (Day/Month) }\end{array}$ & $\begin{array}{c}\text { The Duration from } \\
\text { Sowing to Heading (day) }\end{array}$ & $\begin{array}{c}\text { Maturity Date } \\
\text { (Day/Month) }\end{array}$ & $\begin{array}{c}\text { Growth Period } \\
\text { (day) }\end{array}$ \\
\hline Yezao 1 & $25 / 3$ & $29 / 5$ & 65 & $2 / 7$ & 99 \\
Yezao S & $25 / 3$ & $7 / 6$ & 74 & $9 / 7$ & 106 \\
Yezhuzao S & $25 / 3$ & $6 / 6$ & 73 & $7 / 7$ & $12 / 7$ \\
Zhu 1S & $25 / 3$ & $10 / 6$ & 77 & $8 / 7$ & 109 \\
Hua 819 & $25 / 3$ & $7 / 6$ & 74 & 105 \\
\hline
\end{tabular}

\subsection{Comparison of Seed Dormancy Between the TGMS Lines "Yezao S" and "Yezhuzao S"}

The germination test of newly harvested rice seeds showed that the seed dormancy of different rice varieties were significantly different. "Yezao 1" and "Yezao S" had very strong dormancy, and "Yezhuzao S" had strong seed dormancy, while "Zhu 1S" and "Hua 819" showed no dormancy (Table 3). The occurrence of PHS on "Zhu 1S" and "Hua 819", which had no seed dormancy, were obvious after $48 \mathrm{~h}$ of flooding treatment, but no PHS was found in the other three rice lines with dormant characteristics (Figure 1). The seeds of "Chaling" were harvested in November 2017 and germinated under suitable conditions for seven days. The germination rate is zero (Appendix A).

Table 3. Comparison of germination rate and seed dormancy among different rice lines.

\begin{tabular}{ccc}
\hline Lines & Germination Rate (\%) & Dormancy Level \\
\hline Yezao 1 & 0 & Very strong dormancy \\
Yezao S & 0 & Very strong dormancy \\
Yezhuzao S & $10.3 \pm 1.7$ & Strong dormancy \\
Zhu 1S & $95.3 \pm 2.5$ & No dormancy \\
Hua 819 & $85.0 \pm 2.0$ & No dormancy \\
\hline
\end{tabular}

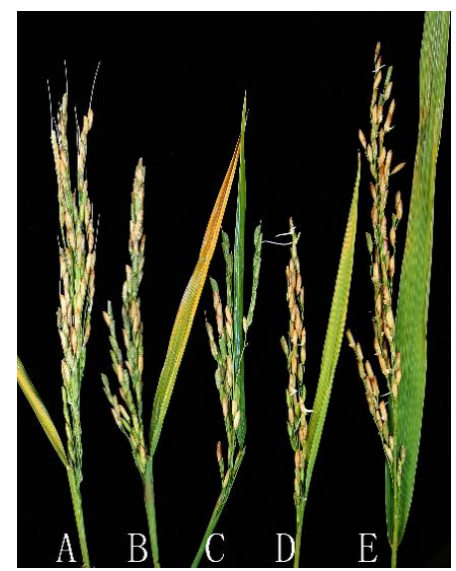

Figure 1. Comparison of PHS in different rice lines. A. Yezao 1; B. Yezao S; C. Yezhuzao S; D. Zhu 1S; E. Hua 819. 


\subsection{Fertility Identification of the Early Rice TGMS Lines "Yezao S" and "Yezhuzao S" with Seed Dormancy}

The pollen fertility of "Yezao S" (Figure 2A,E) and "Yezhuzao S" (Figure 2B,F) were similar after a six-day treatment at $23.5^{\circ} \mathrm{C}$ during the fertile sensitive period; the anthers were small and pollens abortion were observed. After an 18 -day treatment at $20.5^{\circ} \mathrm{C}$, the anthers of "Yezao $\mathrm{S}^{\text {" }}$ (Figure 2C,G) and "Yezhuzao S" (Figure 2D,H) were plumped and the pollens could be stained dark blue. The results showed that the temperature sensitivity of pollen sterility of "Yezao S" and "Yezhuzao $S^{\prime \prime}$ reached the technical security requirements for seed production in the middle and lower reaches of the Yangtze River.

23. $5^{\circ} \mathrm{C}$

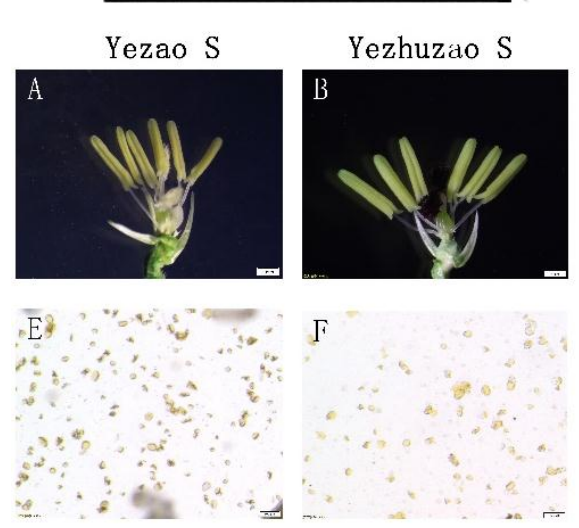

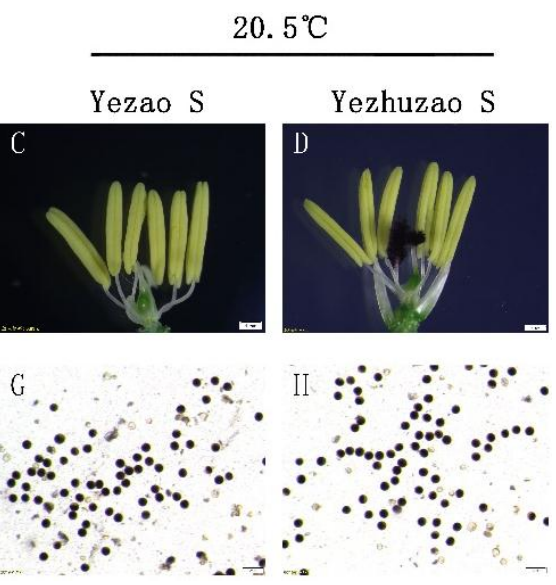

Figure 2. Identification of temperature sensitivity of pollen fertility. (A-H) Anther morphology and pollen fertility of Yezao $S$ and Yezhuzao $S$. Abortive anthers $(\mathbf{A}, \mathbf{B})$ and pollen $(\mathbf{E}, \mathbf{F})$ in Yezao $S$ and Yezhuzao $S$ at the restrictive temperature $\left(23.5^{\circ} \mathrm{C}\right)$. Normal anthers $(\mathbf{C}, \mathbf{D})$ and pollen $(\mathbf{G}, \mathbf{H})$ in Yezao $S$ and Yezhuzao $S$ at the permissive temperature $\left(20.5^{\circ} \mathrm{C}\right)$. Scale bars, $1 \mathrm{~mm}(\mathbf{A}-\mathbf{D})$ and $100 \mu \mathrm{m}(\mathbf{E}-\mathbf{H})$.

\subsection{Comparison of Stigma Exsertion Rate Between the Male-sterile Lines "Yezao S" and "Yezhuzao S"}

After the glumes closed during the flowering stage, whether the stigma is exserted is an important trait affecting the yield of hybrid seed production. When the parents bloom on the same day, the peak time of flowering of the male parent is often earlier and more concentrated than that of the female parent. After the glumes are closed, the female parent has another opportunity to obtain pollen from the male parent at the second and third day if the stigma is exserted, thus improving the outcrossing rate. The stigma exsertion rate of these two male-sterile lines was above 70\% (Table 4, Figure 3), indicating that there is a higher outcrossing rate.

Table 4. Comparison of stigma exsertion rate between "Yezao S" and "Yezhuzao S.".

\begin{tabular}{cccr}
\hline Lines & Single Exerted Stigma (PSES) (\%) & Dual Exerted Stigma (PDES) (\%) & Total Exerted Stigma (PES) (\%) \\
\hline Yezao S & 42.3 & 37.6 & 79.9 \\
Yezhuzao S & 46.3 & 30.5 & 76.8 \\
\hline
\end{tabular}
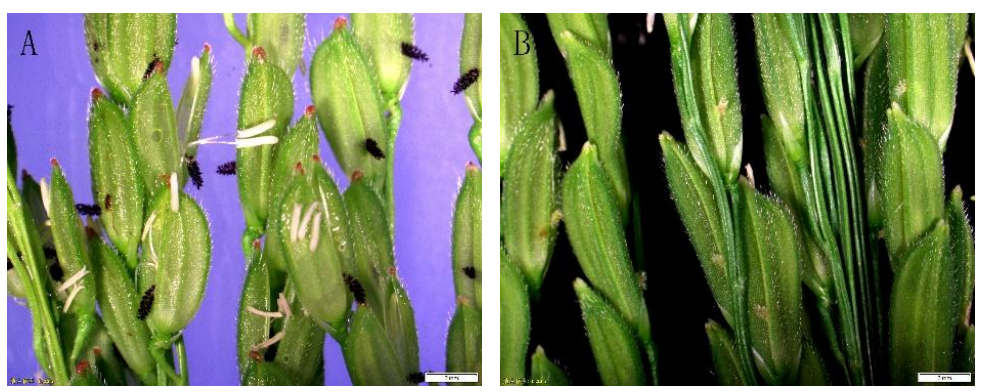

Figure 3. Comparison of stigma exsertion rate in male-sterile lines. Scale bars, $2 \mathrm{~mm}$. (A) "Yezao S" with a black stigma; $(\mathbf{B})$ "Yezhuzao S" with a colorless stigma. 


\subsection{OsNCEDs Expression of Different Rice Lines in Seeds}

The gene expression difference of OsNCEDs in full seed on the 15th day after heading was analyzed, and the results showed that OsNCED2 was not expressed when the seed was in the mature period (Figure 4), indicating that this gene was not involved in the regulation of seed dormancy. The expression of OsNCED1, OsNCED3, OsNCED4, and OsNCED5 at seed maturity indicated that these genes may be related to seed dormancy regulation. The expression of OsNCED1 and OsNCED3 in the seeds of "Yezao 1" was rather high, the expression of OsNCED1 gene in "Yezao S" was significantly higher than that of other OsNCED genes, and the expression of OsNCED5 in "Yezhuzao S" was the highest. The expression of OsNCED1 in "Chaling" was the highest (Appendix B). The expression of OsNCED in the seeds of "Zhu $1 S^{\prime \prime}$ and "Hua 819" was significantly lower than that in the other three rice lines with seed dormancy.

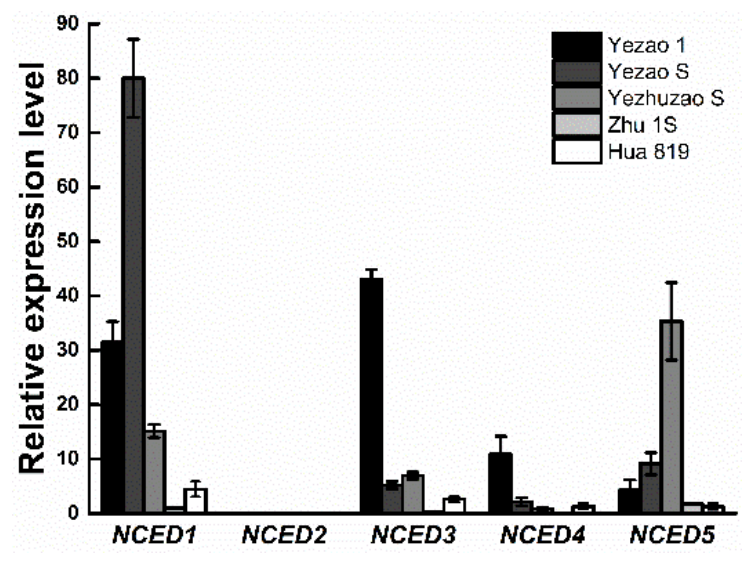

Figure 4. OsNCEDs expression of different rice lines.

\subsection{Comparison of the Difference of ABA Content in Seeds}

In "Zhu 1S" PHS easily occurred the 15th day after heading. The analysis of ABA content on full seeds the 20th day after heading showed that the ABA content in the seeds of "Yezao 1" and "Yezao S" with very strong seed dormancy were highest, while the ABA content of "Yezhuzao S" with strong seed dormancy was significantly higher than that of "Zhu $1 S^{\prime}$ " and "Hua 819", which were prone to PHS (Figure 5).

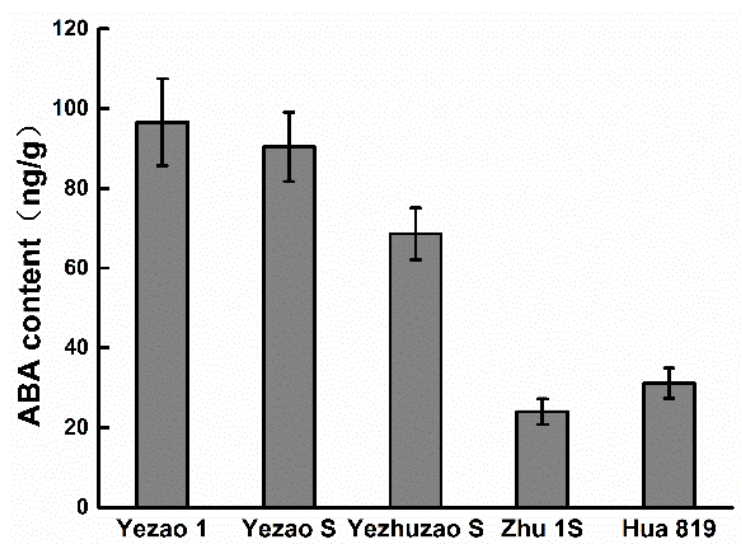

Figure 5. Comparison of the difference of abscisic acid (ABA) content in seeds. 


\section{Discussion}

\subsection{Importance of Seed Dormancy of TGMS Lines on Improving the Quality of Hybrid Seeds}

Based on two-line and three-line hybrid systems, the breeding and theoretical research of hybrid rice has made great achievements [15-20]. At present, the proportion of hybrid rice bred by TGMS lines is increasing, and this is likely due to the pollen fertility of the TGMS lines, which is only regulated by one pair of recessive nuclear genes. With this simple genetic behavior, this method facilitates the selection of a variety of new male-sterile lines and hybrid combinations [4,21-24]. However, there are two technical defects in the TGMS lines. The first is that during the hot season of seed production, cold weather could cause the pollen of male-sterile lines to be fertile, resulting in the failure of hybrid seed production [25-28]. The breeding of double-low male-sterile lines with a low critical temperature of sterility and a low critical temperature of physiological injury is an effective technical approach to improve the security of hybrid seed production $[29,30]$. The second is that the seed production of TGMS lines can only be conducted during the hot season, and seed PHS is prone to occur during rainy days when hybrid rice seeds are at maturity. Therefore, breeding male-sterile lines with seed dormancy is an effective way to prevent PHS and improve seed quality. Another reason for the frequent occurrence of PHS in hybrid rice is that genetic breeders have been working on rapid breeding in Hainan during the winter for many years. After harvesting in mainland China, rice seeds are sown in Sanya in November and returned to the middle and lower reaches of the Yangtze River in March or April of the following year. This breeding method leads to the gradual elimination of dormant rice seed resources, resulting in an increasing amount of fast-germinating rice varieties. In male-sterile lines, the frequency of PHS is the highest in the early rice TGMS line. The very early maturing "Yezao

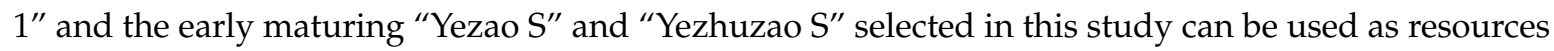
for breeding TGMS lines with seed dormancy.

\subsection{Relationship Between $G A_{3}$ and $A B A$ and the Occurrence of PHS on Hybrid Rice Seeds}

In hybrid seed production by male-sterile rice lines, $\mathrm{GA}_{3}$ is usually applied to promote the heading of male-sterile lines at the initial heading stage, which is an important measure to improve seed production [31,32]. However, $\mathrm{GA}_{3}$ also promotes seed germination; the application of $\mathrm{GA}_{3}$ at the initial heading stage would especially promote the occurrence of PHS on hybrid rice seeds without dormancy. Abscisic acid (ABA) is a sesquiterpenoid that plays a critical role in seed dormancy, stomatal closure, plant development, and biotic/abiotic stress tolerance during the plant life cycle [33,34]. Therefore, the selected dormant TGMS line could have the higher ABA levels than the non-dormant parent Zhu 1S. This could be also beneficial for the resistance to PHS from residual GA effects for promotion of heading. During the mature period, the ABA content on the seeds of the screened male-sterile lines "Yezao 1", "Yezao S," and "Yezhuzao S" of early rice with seed dormancy was significantly higher than that of "Zhu $1 S^{\prime \prime}$ and "Hua 819", which had no seed dormancy and were prone to PHS.

\subsection{Relationship Between OsNCED Regulating ABA Synthesis and Seed Dormancy}

ABA is produced de novo in the ABA biosynthesis pathway, which originates from the catalysis of carotenoid precursors for several enzymes found in higher plants [35]. To date, most ABA biosynthesis genes have been discovered and cloned, including those for zeaxanthin epoxidase (ZEP), 9-cis-epoxycarotenoid dioxygenase (NCED), and abscisic aldehyde oxidase (AAO) [36,37]. The first step of ABA biosynthesis is the cleavage of 9-cis-violaxanthin or 9-cis-neoxanthin by NCED to produce xanthoxin (C15) [38,39]. The first NCED gene to be identified and cloned was VP14 in maize [40] and subsequently, NCED genes were isolated from other plant species [41]. Previous studies have shown that increased NCED transcript levels could promote ABA biosynthesis and increase ABA accumulation in plants [42,43]. In addition, gene expression analysis showed that OsNCED1 has the highest expression level in rice leaves and acts as a housekeeping gene under normal conditions, but it is significantly suppressed by water stress [44]. The knock-out nced3 
mutants and OsNCED3-overexpressing transgenic rice lines suggest that OsNCED3 regulates seed dormancy, stomata aperture, plant growth, abiotic stress tolerance, and leaf senescence by altering ABA accumulation in rice [45]. The results in this study showed that the seed dormancy characteristics of early rice bred from the common wild rice "Chaling" as a dormant gene source were mainly related to OsNCED1, OsNCED3, and OsNCED5 but not OsNCED2. The molecular mechanism of expression differences of these genes requires further study. Understanding these problems is of great significance for breeding male-sterile lines with dormancy characteristics and preventing the occurrence of PHS in hybrid rice seeds.

Author Contributions: Data curation, X.C.; Funding acquisition, Y.T.; Methodology, Y.T.; Project administration, X.L.; Writing—original draft, X.C.; Writing—review \& editing, Y.T. and X.L.

Funding: This work was supported by the Hunan Provincial Natural Science Foundation of China (13JJ2028).

Acknowledgments: Thanks for the guidance of the teacher and the cooperation of all my companion.

Conflicts of Interest: The authors declare no conflict of interest.

\section{Appendix A}

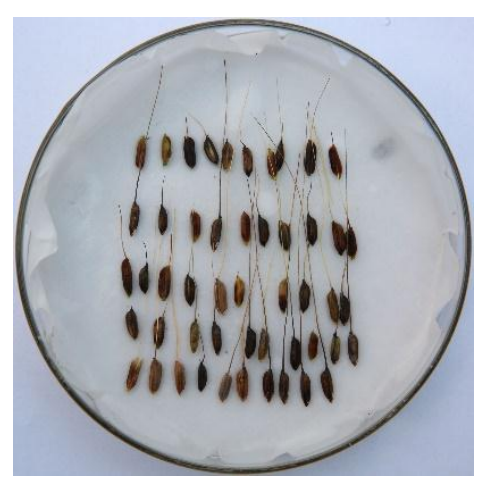

Figure A1. Germination of Chaling wild rice. The seeds were harvested in November 2017 and germinated under suitable conditions for seven days. The germination rate is zero.

\section{Appendix B}

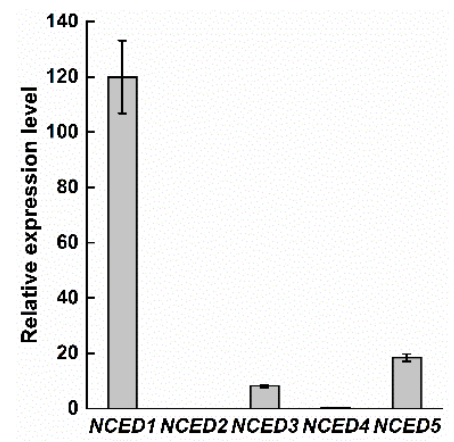

Figure A2. OsNCEDs expression of Chaling. The seeds were harvested at low temperatures in November 2017 and therefore cannot be compared.

\section{References}

1. Lu, X.Y.; Yi, J.H.; Rao, L.Q.; Ma, H.B.; Luo, Z.M. Effects of Temperature and Daylength on Fertility of "ANNONGS-1" and the Mechanism of Its Spollen Abortion. J. Hunan Agric. Coll. 1991, 17, 427-433.

2. Chen, L.B.; Li, X.Z.; Zhou, G.Q. Effects of Temperature on the Sterility of Rice in Photo-sensitive and Thermo-senstive Male Sterile Lines. Acta Agron. Sin. 1993, 19, 47-54. 
3. Si, H.M.; Fu, Y.P.; Liu, W.Z.; Sun, Z.X.; Hu, G.C. Pedigree Analysis of Photoperiod-thermo Sensitive Genic Male Sterile Rice. Acta Agron. Sin. 2012, 38, 394. [CrossRef]

4. Zhou, H.; Zhou, M.; Yang, Y.Z.; Li, J.; Zhu, L.; Jiang, D.G.; Domh, J.F.; Liu, Q.J.; Gu, L.F.; Zhou, L.Y.; et al. RNase Z(S1) processes UbL40 mRNAs and controls thermosensitive genic male sterility in rice. Nat. Commun. 2014, 5, 4884-4893. [CrossRef] [PubMed]

5. Wang, W.F.; Li, S.; Zhong, X.C.; Xiao, C.L.; Yuan, Z.Z.; Yu, C.; Li, Z. Research Progress of Seed Dormancy and Pre-harvest Sprouting of Hybrid Rice. Hunan Agric. Sci. 2013, 5, 10-13.

6. Hu, W.M.; Ma, H.S.; Fan, L.J.; Ruan, S.L. Characteristics of Pre-harvest Sprouting in Sterile Lines in Hybrid Rice Seeds Production. Acta Agron. Sin. 2003, 3, 441-446.

7. Yang, Y.Z.; Tang, P.L.; Yang, W.C.; Liu, A.M.; Chen, Y.Q.; Ling, W.B.; Shi, T.B. Breeding and Utilization of TGMS Line Zhu1S in Rice. Hybrid Rice 2000, 15, 6-9.

8. Liu, A.M.; Ling, W.B.; Shi, T.L. The Major Characteristics of the TGMS Lines Zhu 1S and Lu 18S in Rice. Hybrid Rice 2003, 18, 28-30.

9. Zhou, K.; Fu, L.M.; Wang, Y.H.; Huang, W. Study on Relationship between YieldI and Agronomic Characters of Zhu 1S Series Combinations. Zhongguo Daomi 2014, 20, 86-89.

10. Bewley, J.D. Seed Germination and Dormancy. Plant Cell. 1997, 9, 1055-1066. [CrossRef] [PubMed]

11. Allen, P.S.; Meyer, S.E. Ecological aspects of seed dormancy loss. Seed Sci. Res. 1998, 8, 183-192. [CrossRef]

12. Vleeshouwers, L.M.; Bouwmeester, H.J. A simulation model for seasonal changes in dormancy and germination of weed seeds. Seed Sci. Res. 2001, 11, 77-92. [CrossRef]

13. Misro, B.; Misra, P.K. Certain considerations on seed dormancy in rice. Oryza 1969, 15, 18-22.

14. Li, H.; Yang, Y.Z.; Yao, C.; Liang, M.Z.; Chen, L.B. Studies on Fertility Characteristics of Sensitive to Photoperiod and Temperature of TGMS Lines Zhu 1S and Conditions for it's Multiply. Life Sci. Res. 2008, 12, 158-162.

15. Lin, S.C.; Yuan, L.P. Hybrid rice breeding in China. In Innovative Approaches to Rice Breeding; International Rice Research Institute: Los Baños, Laguna, Philippines, 1980.

16. Cheng, S.H.; Zhuang, J.Y.; Fan, Y.Y.; Du, J.H.; Cao, L.Y. Progress in research and development on hybrid rice: A super-domesticate in China. Ann. Bot. 2007, 100, 959-966. [CrossRef] [PubMed]

17. Normile, D. Reinventing rice to feed the world. Science 2008, 321, 330-333. [CrossRef] [PubMed]

18. He, G.M.; Zhu, X.P.; Elling, A.A.; Chen, L.B.; Wang, X.F.; Guo, L.; Deng, X.W. Global Epigenetic and Transcriptional Trends among Two Rice Subspecies and Their Reciprocal Hybrids. Plant Cell 2010, 22, 17-33. [CrossRef] [PubMed]

19. Si, H.M.; Liu, W.Z.; Fu, Y.P.; Sun, Z.X.; Hu, G.C. Current situation and suggestions for development of two-line hybrid rice in China. Chin. J. Rice Sci. 2011, 25, 544-552.

20. Su, N.; Hu, M.L.; Wu, D.X.; Wu, F.G.; Fei, G.L.; Lan, Y.; Chen, X.L.; Shu, X.L.; Zhang, X.; Guo, X.P.; et al. Disruption of a rice pentatricopeptide repeat protein causes a seedling-specific albino phenotype and its utilization to enhance seed purity in hybrid rice production. Plant Physiol. 2012, 159, 227-238. [CrossRef] [PubMed]

21. Jia, J.H.; Li, C.Y.; Deng, Q.Y.; Wang, B. Rapid constructing a genetic linkage map by AFLP technique and mapping a new gene tms5. Acta Bot. Sin. 2003, 45, 614-620.

22. Wang, Y.G.; Xing, Q.H.; Deng, Q.Y.; Liang, F.S.; Yuan, L.P.; Meng, M.L.; Wang, B. Fine mapping of the rice thermo-sensitive genic male-sterile gene tms5. Theor. Appl. Genet. 2003, 107, 917-921. [CrossRef] [PubMed]

23. Yang, Q.; Liang, C.; Zhuang, W.; Li, J.; Deng, H.; Deng, Q.; Wang, B. Characterization and identification of the candidate gene of rice thermo-sensitive genic male sterile gene tms5 by mapping. Planta 2007, 225, 321-330. [CrossRef] [PubMed]

24. Peng, H.F.; Chen, X.H.; Lu, Y.P.; Peng, Y.F.; Wan, B.H.; Chen, N.D.; Wu, B.; Xin, S.P.; Zhang, G.Q. Fine mapping of a gene for non-pollen type thermosensitive genic male sterility in rice (Oryza sativa L.). Theor. Appl. Genet. 2010, 120, 1013-1020. [CrossRef] [PubMed]

25. Liu, A.M.; Li, B.H. Analysis on the Correlation Between Fertility of TGMS Rice and Temperature. Hybrid Rice 1996, 11, 25-28.

26. Chen, G.H.; Jiang, L.C.; Wei, M.; Wang, G.M.; He, C.N.; Cai, Z.G.; Qiao, Y.X. A preliminary study on the hybrid seed production techniques for rice TGMS lines. Hybrid Rice 1997, 12, 45-46.

27. Chen, G.H.; Jiang, L.C.; Wei, M.; Wang, G.M. A Preliminary Study on Correlation Between Fertility of Thermo-sensitive Genic Male Sterile (TGMS) Rice and Temperature. Agric. Meteorol. 2004, 25, 51-53. 
28. He, Q.; Cai, Y.D.; Xu, Y.W.; Chen, L.Y. Problems and Countermeasures in Utilization of PTGMS Lines in Rice. Hybrid Rice 2004, 19, 1-5.

29. Chen, L.B.; Xu, M.L.; Zhou, G.Q. Selection of PTGMS Lines with Double Low Critical Values in Temperature in Rice. Hybrid Rice 1999, 14, 3-4.

30. Xu, M.L.; Chen, L.B.; Zhou, G.Q.; Liang, M.Z. Temperature Effects on Fertility of Rice TGMS Line Between 96-5-2S with Double Low Critical Temperature Values and Peiai 64S. Acta Ecol. Sin. 2002, 22, 541-547.

31. Pan, W.J. Effect of GA 3 on Elongation of the First Top Internode of M S Lines in Rice. Hybrid Rice 1999, 14, 20-21.

32. Yang, Y.S.; Tang, L.; Liao, F.M.; Li, X.Q.; Liu, A.M.; Wu, X.J. Response of Heading Related Traits to Exogenous Gibberellic Acid (GA3) in Different Rice PTGMS Lines. Hybrid Rice 2012, 27, 57-64.

33. Nambara, E.; Marion-Poll, A. Abscisic acid biosynthesis and catabolism. Annu. Rev. Plant. Biol. 2005, 56, 165-185. [CrossRef] [PubMed]

34. Yu, F.; Qian, L.C.; Nibau, C.; Duan, Q.H.; Kita, D.; Levasseur, K.; Li, X.Q.; Lu, C.Q.; Hui, L.; Hou, C.C.; et al. FERONIA receptor kinase pathway suppresses abscisic acid signaling in Arabidopsis by activating ABI2 phosphatase. Proc. Natl. Acad. Sci. USA 2012, 109, 14693-14698. [CrossRef] [PubMed]

35. Xu, Z.Y.; Kim, D.H.; Hwang, I. ABA homeostasis and signaling involving multiple subcellular compartments and multiple receptors. Plant Cell Rep. 2013, 32, 807-813. [CrossRef] [PubMed]

36. Taylor, I.B.; Burbidge, A.; Thompson, A.J. Control of abscisic acid synthesis. J. Exp. Bot. 2000, 51, $1563-1574$. [CrossRef] [PubMed]

37. Hauser, F.; Waadtl, R.; Schroeder, J.I. Evolution of abscisic acid synthesis and signaling mechanisms. Curr. Biol. 2011, 21, R346-R355. [CrossRef] [PubMed]

38. Tan, B.C.; Schwartz, S.H.; Zeevaart, J.A.; McCarty, D.R. Genetic control of abscisic acid biosynthesis in maize. Proc. Natl. Acad. Sci. USA 1997, 94, 12235-12240. [CrossRef] [PubMed]

39. Milborrow, B.V. The pathway of biosynthesis of abscisic acid in vascular plants: a review of the present state of knowledge of ABA biosynthesis. J. Exp. Bot. 2001, 52, 1145-1164. [CrossRef] [PubMed]

40. Schwartz, S.H.; Tan, B.C.; Gage, D.A.; Zeevaart, J.A.; McCarty, D.R. Specific oxidative cleavage of carotenoids by VP14 of maize. Science 1997, 276, 1872-1874. [CrossRef] [PubMed]

41. Priya, R.; Siva, R. Analysis of phylogenetic and functional diverge in plant nine-cis epoxycarotenoid dioxygenase gene family. J. Plant Res. 2015, 128, 519-534. [CrossRef] [PubMed]

42. Qin, X.; Zeevaart, J.A.D. Overexpression of a 9-cis-epoxycarotenoid dioxygenase gene in Nicotiana plumbaginifolia increases abscisic acid and phaseic acid levels and enhances drought tolerance. Plant Physiol. 2002, 128, 544-551. [CrossRef] [PubMed]

43. Martínez-Andújar, C.; Ordiz, M.I.; Huang, Z.; Nonogaki, M.; Beachy, R.N.; Nonogaki, H. Induction of 9-cis-epoxycarotenoid dioxygenase in Arabidopsis thaliana seeds enhances seed dormancy. Proc. Natl. Acad. Sci. USA 2011, 108, 17225-17229. [CrossRef]

44. Ye, N.; Zhu, G.; Liu, Y.; Li, Y.; Zhang, J. ABA controls $\mathrm{H}_{2} \mathrm{O}_{2}$ accumulation through the induction of OsCATB in rice leaves under water stress. Plant Cell Physiol. 2011, 52, 689-698. [CrossRef] [PubMed]

45. Huang, Y.; Guo, Y.; Liu, Y.; Zhang, F.; Wang, Z.; Wang, H.; Wang, F.; Li, D.; Mao, D.; Luan, S.; et al. 9-cis-Epoxycarotenoid Dioxygenase 3 Regulates Plant Growth and Enhances Multi-Abiotic Stress Tolerance in Rice. Front. Plant Sci. 2018, 9, 162-174. [CrossRef] [PubMed]

(c) 2018 by the authors. Licensee MDPI, Basel, Switzerland. This article is an open access article distributed under the terms and conditions of the Creative Commons Attribution (CC BY) license (http://creativecommons.org/licenses/by/4.0/). 